The hotel is in the 5 star category, which is typical of the whole event. For example, the commentators on the games will include Botvinnik, Karpov, Smyslov, Ehlvest, Sokolov, Yusupov, Ljubojevic, Andersson and Ilescas. Fidelity, Mephisto and CXG have all indicated their intention to participate in the manufacturers' group, and there will be opportunities for computer-chess fans to see the very latest in commercially available chess computers.

Entry forms and details have been sent to a number of prospective participants. Anyone wishing for more information should telephone David Levy in London (624-5551) or Amador Cuesta in Madrid (262-8185).

\title{
TWENTY YEARS ON
}

\author{
David Levy
}

London, England

The year 1988 marks a milestone in the annals of computer chess. It was in August 1968 that I made a bet with Professors Donald Michie and John McCarthy that there would not be, within 10 years, a computer program which could win a match against me. At that time I was extremely confident that I would not meet a serious challenge within 10 years.

One year later Professor Seymour Papert was offered the chance to join the bet. He said that he would happily take the bet for five years from the original date, in other words that he felt that only four more years would be needed. I refused this offer because I felt it would be unfair to take his money under those terms, but he finally agreed to come in on the bet with the others - with 1978 as the crucial year.

When August 1978 came, I played a match against the reigning World Champion CHESS 4.7. The match was played at the Canadian National Exhibition in Toronto and resulted in a win for me by 3 1/2 - $11 / 2$ (three wins, one draw and one loss).

Shortly afterwards $O m n i$ magazine and I offered a prize of $\$ 5,000$ for the first program to win a match against me whenever that might be. The reason was simply that having offered myself as a target to the computer-chess community I did not wish to move (or remove) the target. At about the same time I made another bet, this one for five years, and collected \$ 1,000 from Dan MacCracken in 1984 after I had successfully defended myself against a challenge from CRAY BLITZ, the reigning World Champion. I won that match rather easily, with a score of 4-0.

Now we are all twenty years older than when the first bet was made. I have been surprised at just how much progress has been made during those two decades, and I must admit that within another year or two (three at the outside) I think I will be defeated. I have recently accepted another challenge to play CRAY BLITZ, and if I survive I will wait for a letter from Carnegie-Mellon University, which is breeding mega chess machines at an alarming rate and which I expect to be the home of the program which picks up the Omni Prize.

P.S. If any reader knows the whereabouts of Ed Kozdrowicki, who welched on the original bet, could they please let me know. I am still after my $£ 250,--$ plus ten years' interest! 